\title{
Article
}

\section{Carboxymethylation of Cassava Peel: Effect Sodium Monochloroacetate and Temperature}

\author{
Sperisa Distantina*, Inayati, Fahmi Achmad Saputra, and M. Fitra Arifianto \\ Chemical Engineering Department, \\ Universitas Sebelas Maret, \\ Jl. Ir. Sutami No. 36 A Surakarta, Indonesia. \\ Corresponding author: sperisa_distantina@staff.uns.ac.id \\ distantina@staff.uns.ac.id
}

\begin{abstract}
Cassava peel contains cellulose that can be chemically modified to be more useful product. In this work, carboxymethylcellulose (CMC) from cassava peel powder was prepared by alkalization using sodium hydroxyde and then followed by carboxymethylation using sodium monochloroacetate. The aims of this work were to investigate the effect of sodium monochloroacetate-powder ratio $(0.59,1.47,2.95,4.42)$ and carboxymethylation temperature $\left(45^{\circ} \mathrm{C}\right.$ and $70^{\circ} \mathrm{C}$ ) on the degree of substitution (DS) and reaction efficiency (RE). The result of FTIR spectra indicated that carboxylmethyl groups successfully attached on the cellulose backbone to form CMC structure. The higher of sodium monochloroacetate-powder ratio and higher carboxymethylation temperature enhanced its DS but reduced the RE.
\end{abstract}

Keywords: cassava peel; carboxymethylation, carboxymethyl-cellulose; degree of substitution

EQUILIBRIUM Volume 2 No.1 January 2018

Online at http:/ / equilibrium.ft.uns.ac.id 


\section{Introduction}

Cassava (Manibot esculenta Crantz) is the third food-based in Indonesia after rice field and corn. The production of cassava in Indonesia was more than 24 million ton in 2012 ( $5^{\text {th }}$ ranked in the world). Sixteen percent of the total weight of cassava is cassava peel. It shows that the waste of cassava peel reaches almost 3.84 million ton each year.

The cassava peel is polysaccharide containing cellulose and starch. Due to the presence of hydroxyl groups in repeated unit of the polysaccharides chain, the cassava peel may be chemically modified in order to get a new material with better functional properties. Carboxymethylcellulose (CMC) is a green polymer with great important in pharmacy, medicine, cosmetics, and food industries. CMC is generally made from raw material wood pulp. By using alternative raw materials from unused cassava peel, it will indirectly affect the reduction of tree-cutting action by the producer of CMC.

$\mathrm{CMC}$ can be made from the cellulose into form of $\mathrm{Na}-\mathrm{CMC}$ in a way alkalization with $\mathrm{NaOH}$ and then carboxymethylation with sodium monochloroacetate (Na-MCA). The quality of the CMC can be seen from the number of carboxyl groups attached to the cellulose. The number of carboxyl groups attached to the powder, is known as degree of substitution (DS). The ratio of reagent Na-MCA as carboxymethylation reagent and powder material is one of parameters that affects the value of DS [1].

The aims of this research were to determine the effect of carboxymethylation parameters, namely the ratio of sodium monochloroacetic-cassava peel powder and temperature of carboxymethylation on the degree of substitution and reaction efficiency. The changes of chemical structures during CMC preparation were confirmed by FTIR measurement.

\section{Materials and Methods}

\section{A. Materials}

Polysaccharide material that used in this research was cassava peel obtained from local market. Cassava peel was crushed, dried, and sieved into 50 mesh screen. The undersize product was collected as cassava peel powder and kept in dry until further processing was done. Another chemical materials used, namely $\mathrm{ClCH}_{2} \mathrm{COONa}(\mathrm{Na}-\mathrm{MCA}), \mathrm{NaOH}, \mathrm{C}_{2} \mathrm{H}_{5} \mathrm{OH}, \mathrm{HCl}$, and other chemicals were purchased and used without further purification.

\section{B. CMC Preparation}

The CMC preparation was based on the previous researcher method [2]. Preparation of CMC was done with 2 processes separately and respectively. The first process was alkalization. Five grams of cassava peel powder, $10 \mathrm{ml}$ ethanol $80 \%$, and $28 \mathrm{mmol} \mathrm{NaOH}$ were mixed and stirred with magnetic stirrer at $25^{\circ} \mathrm{C}$ in three neck rounded flask for 5 minutes. The second process was carboxymethylation. In this step, the Na-MCA was added into the mixture produced by previous alkalization. The molar ratio of of sodium monochloroacetate-cassava peel powder, called as reagent-powder molar ratio (RPMR), was varied for 0.59. 1.47, 2.95, and 4.42. The mixture was then heated up to $45^{\circ} \mathrm{C}$ for 60 minutes and continuously stirred using magnetic stirrer. To study the effect of carboxymethylation temperature, the carboxymethylation was carried out at $45^{\circ} \mathrm{C}$ and $75^{\circ} \mathrm{C}$.

\section{CMC Purification}

CMC product was purified by immersing it in ethanol $80 \%$, and then the CMC was filtered and dried at temperature $100^{\circ} \mathrm{C}$ until a constant weight was attained.

\section{FTIR Analysis}

Molecular groups were identified using FTIR spectrometer (Shimadzu IR Prestige-21). Prior to the FTIR test, samples were powdered and was formed into pellet using $\mathrm{KBr}$ powder. Transmission was measured at the wave number range of $4500-500 \mathrm{~cm}^{-1}$.

\section{E. Determination of DS}

The DS value was determined by back titration method [3]. Firstly, CMC must be changed into H-CMC. Five grams of $\mathrm{CMC}$ was dissolved in $100 \mathrm{ml} \mathrm{HCl} 1.8 \mathrm{M}$ by continuously stirred for 30 minutes. The dispersion 
was then filtered. In order to remove the excess acid, the precipitate was washed using ethanol, until the conducivity of the filtrate was about $25 \mathrm{us} / \mathrm{cm}$. Then, the precipitate dried at $50^{\circ} \mathrm{C}$ for 2 hours.

After H-CMC was formed, the H-CMC was converted into soluble sodium salt. The value of DS was determined using back titration method. The 0.5 grams $\mathrm{H}-\mathrm{CMC}$ was dissolved in $20 \mathrm{~mL}$ of $0.2 \mathrm{M} \mathrm{NaOH}$ and added aquadest so that the volume of the solution became $100 \mathrm{~mL}$. The $25 \mathrm{~mL}$ of the solution was poured into an erlenmeyer flask and diluted by addition of distilled water. The excess of $\mathrm{NaOH}$ was back-titrated using standard $0.05 \mathrm{M} \mathrm{HCl}$, and phenolphtalein was used as the indicator. The titration was repeated for three times and the average value of the $\mathrm{HCl}$ volume was used for the calculations data. A blank was also titrated. The number of $\mathrm{COOH}$ was determined using equation (1).

$$
n \operatorname{cooh}=(v b-v) \times M H C l \times 4
$$

Where $\mathrm{vb}$ and $\mathrm{v}$ (in $\mathrm{mL}$ ) is the volume of $\mathrm{HCl}$ for titration of the blank and the sample, respectively. $\mathrm{MHCl}$ (in $\mathrm{mol} / \mathrm{L}$ ) is the $\mathrm{HCl}$ concentration and 4 is the ration of the total volume $(100 \mathrm{~mL})$ and the volume taken for titration $(25 \mathrm{~mL})$.

The DS was calculated using equation (2).

$$
\mathrm{DS}=\frac{162 \times \mathrm{ncooh}}{\mathrm{mds}-(58 \times \mathrm{ncooh})}
$$

Where $162 \mathrm{~g} / \mathrm{mol}$ is the molar mass of an anhydroglucose unit (AGU); ncooh (in mol) is the amount of $\mathrm{COOH}$ calculated from the obtained value of equivalent volume; $58 \mathrm{~g} / \mathrm{mol}$ is the net increase in the mass of an AGU for each carboxymethyl group substituted. The mds (in gram) is the mass of dry sample calculated from known sample mass ms (in gram) and the water content (wwater). The mds is calculated using equation (3).

$$
\text { mds }=\left(1-\frac{w \text { water }}{100}\right) \times \mathrm{ms}
$$

The reaction efficiency (\%RE) was calculated by method proposed by [2] and using equation (4).

$$
\% \mathrm{RE}=\frac{\mathrm{DS} \times 100}{\mathrm{RSMR}}
$$

\section{Results and Discussion}

The quality of CMC can be shown by the amount of carboxyl groups attaching in polysaccharide. In this research, the presence of attached carboxyl group was confirmed by FTIR spectra and the degree of substitution value.

Sodium monochloroacetate reacted with cassava peel powder in the presence of sodium hydroxide to form carboxymethylcellulose. The process involved two main reactions as depicted in equation (5), (6), and (7).

$$
\text { Cel-OH }+\mathrm{NaOH} \longrightarrow \text { Alkalization } \longrightarrow \text { Cel-ONa }+\mathrm{H}_{2} \mathrm{O}
$$

Cel-ONa $+\mathrm{Cl}-\mathrm{CH}_{2} \mathrm{COONa}$ Carboxymethylation $\quad \mathrm{Cel}-\mathrm{OCH}_{2} \mathrm{COONa}+\mathrm{NaCl}$

Overall, the reaction can be written as follows:

Cel-OH $+\mathrm{Cl}-\mathrm{CH}_{2} \mathrm{COONa} \stackrel{\mathrm{NaOH}}{\longrightarrow} \mathrm{Cel}-\mathrm{OCH}_{2} \mathrm{COONa}+\mathrm{H}_{2} \mathrm{O}+\mathrm{NaCl}$

The hydrolysis reaction leads the removal of sodium monochloroacetate during side reactions with formation of sodium glycolate [2]. 


\section{F. FTIR Spectra}

The native starch and CMC samples were analysed by FTIR, which could be depicted in the two spectra in Fig. 2. Native starch was cassava peel powder sample that used as raw material for preparing CMC. CMC sample was prepared by carboxymethylation with $45^{\circ} \mathrm{C}$ and RPMR for 4.42 . The $\mathrm{x}$-axis represents the wavelength $\left(\mathrm{cm}^{-1}\right)$ and $\mathrm{y}$-axis respresents the light transmittance through the sample. The FTIR spectrum of the sample shows that the carboxyl, methyl, and hydroxyl functional groups are found at wavelength of 1100, $1300,1600,3400 \mathrm{~cm}^{-1}$, respectively.

Fig. 1 shows the spectra of carboxymethyl cellulose from cassava peel. The presence of a new and strong absorption band of $1609 \mathrm{~cm}^{-1}$ was reffered to the COO- group. The arrow $(\uparrow)$ from the figure shows that there was COO- group attached in the cellulose. It is an evidence that hydroxyl group of cellulose was succesfully replaced with carboxyl group when carboxymethylation reaction occured. In CMC prepared from palm kernel cake, the carboxyl groups and its salts wave numbers were $1604 \mathrm{~cm}^{-1}$ and $1421 \mathrm{~cm}^{-1}$ [4]. In CMC prepared from cellulose, the carboxyl groups and its salts wave numbers were $1563 \mathrm{~cm}^{-1}$ and $1419 \mathrm{~cm}^{-1}$ [5].

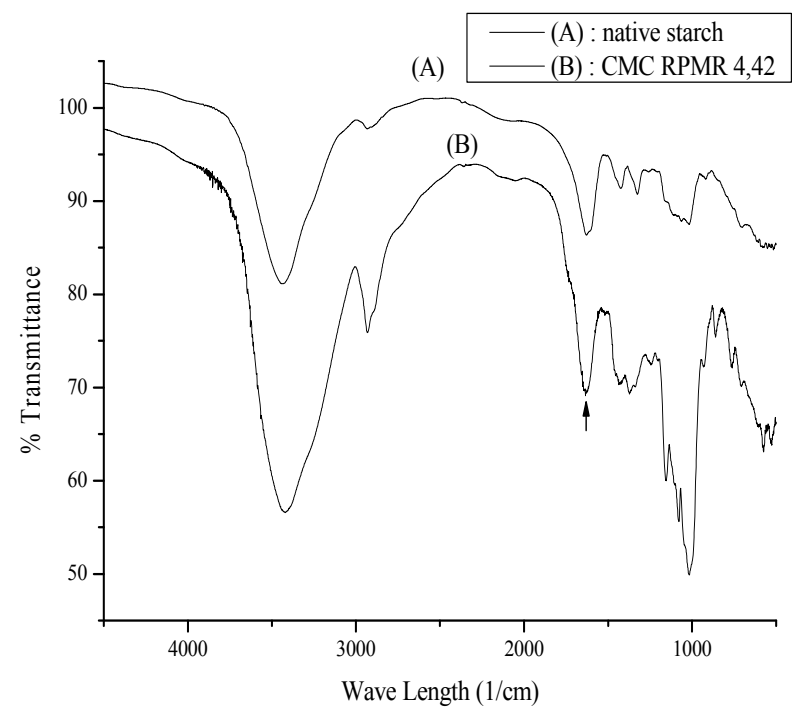

Figure. 1. Ftir Spectra of Cassava Peel Powder (A) and Prepared CMC (B)

G. The Effect of Reagent-Powder Molar Ratio (RPMR) on the Degree of Substitution

Fig. 2 shows the relationship between DS with RPMR and \% RE with RPMR at carboxymethylation temperature for $45^{\circ} \mathrm{C}$. The effect of RPMR was investigated at RPMR 0.59, 1.47, 2.95, and 4.42. From Fig. 2, it can be seen that there was a trend that with the more of RPMR, the DS was higher. The higher of RPMR indicated the higher content of carboxyl in the reactant mixture. Thus the more substitution of functional group occured. 


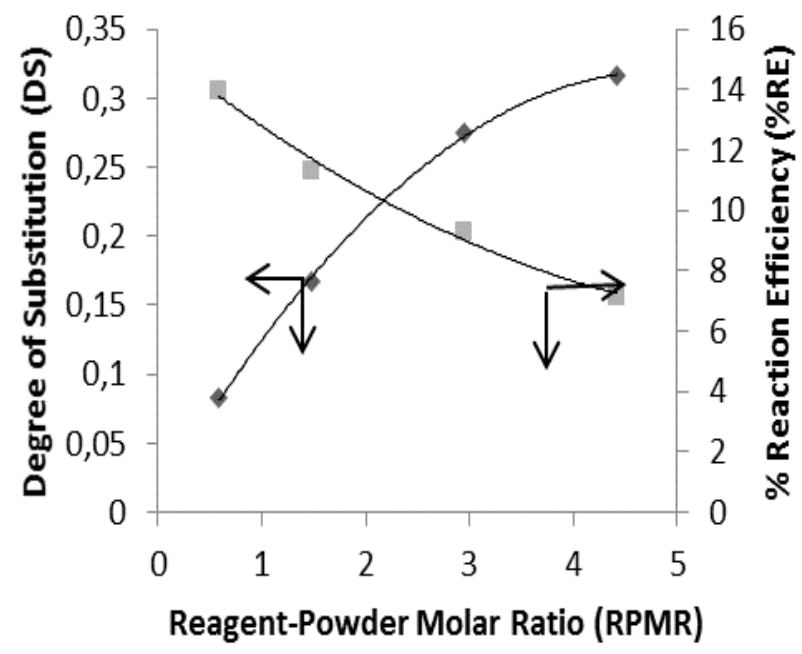

Figure 2. Effect of Reagent-Powder Ratio on DS and RE

However, the more RPMR, the reaction efficiency was lower. The higher of RPMR expressed the increasing amount of Na-MCA. In the alkaline reaction medium, these Na-MCA tend to produce sodium glycolate [2]. In this experiment data range, the optimum RPMR was 2.1 where the DS was 0.22 and RE was $10.45 \%$ (Fig. 2).

$H$. The Effect of Temperature on the Degree of Substitution

Table 1 shows the value of DS of sample with different carboxymethylation temperature. The effect of temperature on degree of substitution was investigated by varying the temperature from $45^{\circ} \mathrm{C}$ to $70^{\circ} \mathrm{C}$. Table 1 shows when the carboxymethylation temperature was increased, the DS was higher. It was known that enhancement of the reaction temperature will increase reaction rate as shown by Arhenius equation. Higher temperature increased the rate of reaction, so that the more number of carboxylmethyl groups attaching in CMC as described by the higher value of DS.

Table 1. Effect of Temperature on Degree of Sustitution

\begin{tabular}{ccc}
\hline $\begin{array}{c}\text { Temperature } \\
\left({ }^{\circ} \mathrm{C}\right)\end{array}$ & RPMR & DS \\
\hline \multirow{2}{*}{45} & 2.95 & 0.2744 \\
& 4.42 & 0.3164 \\
70 & 2.95 & 0.6267 \\
& 4.42 & 0.7588 \\
\hline
\end{tabular}

\section{Conclusion}

Based on FTIR spectra and DS of sample, CMC can be prepared from cassava peel powder. The increasing of sodium monochloroacetic-powder ratio and carboxymethylation temperature enhanced the DS but decreased the RE.

\section{Acknowledgment}

We would like to thank the Directorate of Higher Education, Ministry of national Education, Indonesia, for financial support of this work through 'mandatory research grant' 2015, Universitas Sebelas Maret, Surakarta. 


\section{References}

[1] T. Spychaj, K. Wilpiszewska, and M. Zdanowicz, "Medium and high substituted carboxymethyl starch: synthesis, characterization and application”, Starch, 65, 22-33, 2013.

[2] L. M. Nwokocha and G.B. Ogunmola, "Carboxymethylation of Cassava Starch in Different Solvents and Solvent-Water Mixtures: Optimization of Reaction Conditions”, J. Applied. Sci., 8, 1581-1585, 2008.

[3] Z. Stojanovic, K. Jeremic, S. Jovanovic, and M.D. Lechner, "A comparison of some methods for the determination of the degree of substitution of carboxymethyl starch", Starch, 57, 79-83, 2005.

[4] A. Bono, P.H. Ying, F.Y. Yan, C.L. Muei, R. Sarbatly, D. Krishnaiah, "Synthesis and Characterization of Carboxymethyl Cellulose from Palm Kernel Cake”, Adv. in Nat. Appl. Sci., 3(1): 5-11, 2009.

[5] N. M. Ismail, A., Bono A. C. R., Valintinus, S. Nilus and L. M. Chang, "Optimization of Reaction Conditions for Preparing Carboxyl Methyl Cellulose”, 10 (21), 2530-2536, 2010. 